\title{
Impact of tillage intensity on clay loam soil structure
}

\author{
Omar Daraghmeh ${ }^{*}$, Carsten Petersen ${ }^{1}$, Lars Munkholm ${ }^{2}$, Liubava Znova ${ }^{3}$, Peter Bilson Obour ${ }^{2}$, \\ Søren Kirkegaard Nielsen ${ }^{3}$, Ole Green ${ }^{3}$. \\ *Corrseponding author, email: o.daraghmeh@plen.ku.dk \\ ${ }^{1}$ Department of Plant and Environmental Sciences, Section for Environmental Chemistry and \\ Physics, University of Copenhagen, Thorvaldsensvej 40, 6. Sal, T645, 1871 Frederiksberg C, \\ Denmark. \\ ${ }^{2}$ Department of Agroecology, Aarhus University, Research Centre Foulum, Blichers Allé 20, \\ P.O. Box 50, DK-8830 Tjele, Denmark \\ ${ }^{3}$ AGROINTELLI, Agro Food Park 13, Skejby, 8200 Aarhus N, Denmark.
}

\section{Introduction}

Soil structure and structural stability are key parameters in sustainable soil management and optimum cropping practices. Reduced and traditional tillage often results in substantial temporal and spatial variability of soil structure (e.g., Daraghmeh et al., 2009). However, locally and temporally adapted precision tillage may reduce such variability and thereby improve crop performance while at the same time reduce environmental impacts. Excessive dispersion of clay and silt particles from destabilized aggregates near the surface including not least wheel track areas will accelerate clogging. Clogging and slow infiltration may lead to surface runoff, water erosion and pollution of surface waters (Czyż and Dexter 2015; Petersen et al., 2016). Precision tillage based on accurate and online information about the soil has only to a limited extent been adopted so far, but novel sensors and data integration techniques may pave its way (Pedersen, 2004). We conducted a field experiment on a clay loam soil with seedbed preparation by rotovation after winter ploughing and with the following factors: operational speed, rotovation speed, wheeling after rotovation, and soil moisture content. All factors were varied within realistic and practical limits. The objective was to investigate the potential of regulating soil structure and structural stability by regulating tillage intensity.

\section{Materials and methods}

A field experiment with seedbed preparation by rotovation was conducted $20 \mathrm{~km}$ west of Copenhagen in the spring and summer of 2017. Treatments were applied in a randomized complete block design with three blocks and two main factors on April 19 at "optimal" soil moisture content (ca. $22 \mathrm{~g} / \mathrm{g}$ ), i.e. operational speed (OS) at two levels $(2.9$ and $6.3 \mathrm{~km} / \mathrm{h}$ ) and rotovation speed (RS) at three levels $(450,545$, and $630 \mathrm{rpm})$. Three extra treatments were included, i.e. rotovation $(\mathrm{OS}=2.9 \mathrm{~km} / \mathrm{h}$; RS=545 rpm) followed by wheeling at "optimal" and "high" soil moisture contents, respectively, and rotovation $(\mathrm{OS}=2.9 \mathrm{~km} / \mathrm{h} ; \mathrm{RS}=545 \mathrm{rpm})$ at "high" soil moisture content without wheeling. Rotovation depth was kept constant at approximately $8.0 \mathrm{~cm}$. The ratio of the amount of clay- and silt-sized particles dispersed by shaking to the estimated total amount of clay- and silt-sized particles in the sample based on the texture analysis from the specific plot $(\mathrm{g} / \mathrm{g})$ was used to express soil dispersibility. Portions representative subsamples were air-dried and subjected to standardized, gentle shaking on a nest of sieves with apertures: $32,16,8,4$ and $2 \mathrm{~mm}$ to determine aggregate size distribution. The degree of fragmentation after tillage was expressed as geometric mean diameter. 


\section{Results and discussion}

The specific energy input was significantly larger with low operation speed (OS1=2.9 $\mathrm{km} \mathrm{hr}^{-1}$ ) than with high operation speed (OS2 $=6.3 \mathrm{~km} \mathrm{hr}^{-1}$ ) (on average 116 and $52 \mathrm{~J} \mathrm{~kg}^{-1}$, respectively), and significantly larger for the high rotation speed than the low rotation speed $\left(105 \mathrm{~J} \mathrm{~kg}^{-1}\right.$ for OS3 compared to $54 \mathrm{~J} \mathrm{~kg}^{-1}$ for RS1). The proportion of large aggregates $(<32 \mathrm{~mm})$ tended to be smaller for the high operation speed treatment than the low operation speed. This could be interpreted as low operation speed, may have resulted in kneading of the smaller soil particles rather than crumbling due to relatively high soil moisture content (Lernik, 1990). Soil moisture condition is one of the important soil properties that influence soil fragmentation during tillage (Obour et al., 2017). Soil dispersibility was larger right after tillage (at T1) reaching at least 0.6 $\mathrm{g} / \mathrm{g}$ after $40 \mathrm{~min}$ than after 45 days (at T2) when the dispersibility was less than $0.4 \mathrm{~g} / \mathrm{g}$ for all treatments except in wheel tracks. Results showed a significant increase of soil dispersibility $\left(\mathrm{R}^{2}=0.54\right)$ with increasing the rotation speed at the higher operation speed (OS2) until a breaking point $79.8 \mathrm{~J} \mathrm{Kg}^{-1}$, subsequently a slightly reduction of the dispersibility with increasing the rotation speed at the highest energy input (OS1) was found. Our results agreed with Watts et al. (1996) findings, that the amount of mechanically dispersible clay was a function of both soil water content and specific energy input. Results showed that increasing tillage intensity resulted in a clear increase of proportion medium $(8-16 \mathrm{~mm})$ aggregate fraction until a breaking point $73.0 \mathrm{~J} \mathrm{Kg}^{-1}$ whereas, after this point results showed a slight increase in these aggregate fraction. Results indicated that increasing tillage intensity resulted in a clear reduction of the small aggregate proportion until a breaking point $79.7 \mathrm{~J} \mathrm{Kg}^{-1}$ whereas, after this point results showed a slight decrease in these aggregate fraction. A highly significant negative correlation $\left(\mathrm{R}^{2}=0.69\right)$ between the soil dispersibility and the specific area of the aggregate was recorded. Increasing specific area resulted in decreasing the soil dispersibility. This increase of specific area is a direct result of increasing the fraction of the aggregates $<4 \mathrm{~mm}$, as it is indicated in the negative correlation $\left(\mathrm{R}^{2}=0.71\right)$ between the soil dispersibility and fraction of aggregate less than $4 \mathrm{~mm}$. Increasing geometric mean weight diameter resulted in decreasing the soil dispersibility $\left(\mathrm{R}^{2}=0.66\right)$.

\section{Conclusions}

Results showed a clear impact on topsoil structure produced by either intensive tillage or wheel machine compaction. Increasing energy input resulted in reducing soil structure stability as represented by soil dispersibility. Operation speed and rotation speed have either as individual or combined significantly affect topsoil soil structure characteristics. Wheel machine compaction clearly resulted in differences in aggregate size distribution, tensile strength, rupture energy, soil dispersibility, and air permeability.

\section{References}

1. Czyż, E. and Dexter, A. (2015). Mechanical dispersion of clay from soil into water: readily dispersed and spontaneously dispersed clay. International Agrophysics, 29(1), pp. 31-37.

2. Daraghmeh O.A., Jensen J.R., Petersen C.T. (2009): Soil structure stability under conventional and reduced tillage in a sandy loam. Geoderma, 150: 64-71.

3. Obour, P. B., Lamandé, M., Edwards, G., Sørensen, C. G. and Munkholm, L. J. (2017), Predicting soil workability and fragmentation in tillage: a review. Soil Use Manage, 33: 288298. 